\title{
Gene transfer through the use of sublethally irradiated pollen: the theory of chromosome repair and possible implication of DNA repair enzymes
}

\author{
K. K. Pandey
}

Genetics Unit, Grasslands Division, DSIR, Palmerston North, New Zealand.

Gene transfer experiments using sublethally irradiated pollen have given inconsistent results, with the species used falling generally into two classes: (a), those in which the M1 plants, arising from the use of irradiated pollen, are highly variable and show a "maternalisation effect", many plants lacking one or more dominant markers from the irradiated parent and (b), those in which the M1 plants are generally alike and similar to the F1 plants obtained by the use of unirradiated pollen, and there is no maternalisation effect. It is suggested here that this difference relates to the absence (a) or presence (b) of certain chromosome and DNA repair enzymes in the pollen, for which, it is argued, plant species may be widely variant and "polymorphic". The proposal is in agreement with the theory of chromosome repair through somatic recombination and gene conversion previously invoked to explain the maternalisation effect and gene transfer through the use of sublethally irradiated pollen.

\section{INTRODUCTION}

Reported transfer of single genes (Pandey, 1975, $1978,1980 a, b, 1981)$ or a part of the male nuclear complement rather than the whole male nucleus (Jinks et al., 1981; Caligari et al., 1981; Pandey, 1983a; Powell et al., 1983; Snape et al., 1983; Zamir, 1983; Banga et al., 1984; Caligari et al., 1984; Davies, 1984; Daskalov, 1984), between one plant and another by the use of irradiated pollen is of considerable interest to the plant breeder. The procedures, when better understood, have the potential of not only considerably expediting plant, and possibly animal (Pandey, 1980c; Pandey and Patchell, 1982) breeding but also producing desirable recombinants which could not be produced before because of close linkage between desirable and undesirable genes, or because of inviability of the normal hybrid zygotes or complete sterility of the normal hybrids.

To date, gene transfer by irradiated pollen has been achieved in two distinct ways, dependent on the dose of radiation used. (a) Following application of pollen irradiated with a very high, lethal dose $(60-100 \mathrm{Kr})$, there may be no normal fertilisation and syngamy and the whole, or nearly whole, paternal genome may be eliminated or excluded. However, the egg nucleus, usually held up in the
G1 phase, may be stimulated to resume the cell cycle and during replication some DNA fragments from the irradiated pollen may be incorporated into the new egg chromosomes. The first cell division fails and the resulting parthenogenetic embryo is basically maternal diploid except for one or a few identifiable genes from the irradiated pollen. The phenomenon is termed "egg-transformation" (Pandey, 1978, 1981). (b) If the donor pollen is irradiated heavily but sublethally, for example between $2 \mathrm{Kr}$ and $30 \mathrm{Kr}$, or higher (Banga et al., 1984), depending upon the species and combination, the nuclei are damaged but not functionally and physically incapacitated, and normal fertilisation occurs, as exemplified by studies of intraspecific crosses in Nicotiana rustica (Jinks et al., 1981; Caligari et al., 1981) and Zea mays (Pandey, 1983a) and interspecific crosses between N. glutinosa and N. tabacum (Pandey and Phung, 1982). The M1 progeny obtained in N. rustica and $Z$. mays, were extremely variable in phenotype regarding the marker genes, in contrast to the F1 progeny arising from normal crosses which were relatively uniform in appearance and showed dominant characteristics of the pollen parent. The M1 progeny showed varying degrees of resemblance to either parent, as well as different combinations of characters controlled by recessive 
and dominant major genes. However, they were more maternal in characteristics than true hybrids, and in $N$. rustica, where seeds were produced with different sublethal doses, this "maternalisation" increased with dose. The M2 progenies in N. rustica, while showing significant heterogeneity, again resembled the maternal parent more than the normal F2 progeny, the similarity increasing with dose. A similar situation was also observed with regard to quantitative characters. The phenomenon is not well understood, but it is not egg-transformation. In effect, it results in partial hybridisation, only a certain proportion of the paternal genome combining with the maternal genome.

\section{SUBLETHALLY IRRADIATED POLLEN}

Caligari et al. (1981) proposed three possible explanations for the maternalisation phenomenon in $N$. rustica resulting from the use of sublethally irradiated pollen: (a) Radiation-induced "mutations", in the broadest sense, including deletions, may be responsible for these changes. However, since mutations are usually random, they are not likely to bring about a consistent, maternally oriented change. (b) Radiation-induced inactivation of a large part of the paternal genome would have a similar effect. Such an effect, however, would have to be permanent to be displayed consistently in both M1 and M2 generations. This type of large-scale "silencing" effect on the genome is unknown, and is very difficult to reconcile with most mutation studies. (c) Egg-transformation and parthenogenetic diploidy, similar to that envisaged for lethally irradiated pollen in certain other species of Nicotiana (Pandey, 1980a, b). However, experiments with a number of species, including parents having different chromosome numbers, have shown that sublethal levels of pollen irradiation usually allow normal fertilisation and sexual progeny (Brewbaker and Emery, 1962; VassilevaDryanovska, 1966). Furthermore, parthenogenetic diploidy, irrespective of the level of lethal dose, consistently produces highly fertile maternal progeny and not varyingly fertile, dissimilar progeny, as found here. The increasing frequency of sterile M1 plants occurring with the rise in dose is consistent with normal fertilisation. Transfer of complex and quantitative characters as well as relatively simply inherited characters also supports the concept of normal fertilisation rather than single gene transfers. None of the three proposed mechanisms therefore explained the observations satisfactorily.
To explain the observations in maize, Pandey (1983a) suggested that during early embryogeny following normal fertilisation by sublethally irradiated pollen there may be selection of cells in which radiation-damaged segments of paternal chromosomes have been repaired, through homologous somatic recombination and gene conversion, by segments from the normal maternal chromosomes. The chromosome repair may be specially facilitated by radiation-induced subchromatid breakage, which particularly occurs in the prophase of mitotic cells (Evans, 1962), the usual phase of the generative and gametic nuclei in the pollen grains at the time of irradiation (D'Amato, 1977). Also, there is evidence to suggest that mature gametes may be deficient in DNA repair enzymes (Leigh, 1976; Mittler, 1982), which allows certain specific damages to remain unrepaired. Following fertilisation, when the repair enzymes are restored in the developing diploid phase, the loose single strands produced in the paternal chromosomes may promote somatic pairing between normal homologous, maternal chromosomes and damaged, paternal chromosomes, resulting in recombination and gene conversion. "Aggressive" homologous pairing appears to be an inherent property of single-stranded DNA (Dressler and Potter, 1982). The developing embryo may thus not only be relieved of the radiation damage, but in the process may also become significantly maternal in characteristics. The phase of the pollen nuclei at the time of irradiation may therefore be critical in endowing the irradiated gametes with the special features resulting in the present phenomenon. Mechanisms of mitotic and meiotic recombination and gene conversion, particularly in relation to the lower eukaryote yeast, have been expertly reviewed recently by Esposito and Wagstaff (1981) and Fogel et al. (1983).

Experiments in barley, Hordeum vulgare (Powell et al., 1983), wheat, Triticum aestivum (Snape et al., 1983) and Indian mustard, Brassica juncea (Banga et al., 1984), gave similar results to those with $N$. rustica and $Z$. mays. There was maternalisation of M1 and M2 progenies, which increased with dose. In $B$. juncea, apparently there is considerable parthenogenetic matromorphy with the use of heavily irradiated pollen. In Triticum aestivum, which is an allohexaploid, the efficiency of the phenomenon is reduced possibly owing to radiation-induced loose single strands from the damaged paternal genome being paired with the homologous regions not only in their own homologous genome, but also in the homoeologous genomes present in the same nucleus, thus causing 
increased sterility. There is evidence from other studies including tissue culture that under certain conditions there may be a relaxation of pairing suppression between homoeologues (Orton and Steidpl, 1980). The cytological aberrations described by Snape et al. in wheat are in accord with this suggestion. The results in wheat led Snape et al. (1983) to the following conclusions: (a) A certain proportion of the paternal genome is eliminated early in development of the embryo resulting in hemizygosity, so that subsequent progeny can only contain maternal alleles. (b) Other loci are heterozygous in the M1 but in some cases the maternal allele is transmitted to surviving M2 progeny at a higher frequency than the paternal alleles. These processes appeared to be random with respect to the loci and chromosomes affected. However, deletions of the magnitude and complexity required to produce the observed high degree of maternalisation are not likely to be fertile or even viable. Furthermore, usually most radiation-induced deletions in the pollen are not transmissable to the next (M2) generation (Rick and Khush, 1969).

The use of irradiated pollen as a possible means of expediting gene transfer was tested by Zamir (1983) in tomato, where a number of convenient codominant isozyme markers are available. Pollen from the wild tomato species Solanum pennellii was irradiated with gamma rays at various doses and used in crosses with Lycopersicon esculentum as female. The results clearly demonstrated that the marked maternalisation of the M1 and following segregation progenies found in other materials studied was absent in tomato. Shifts of segregation ratios which did occur gave excess of either maternal or paternal alleles. Similar results were also obtained in intraspecific crosses in Pisum sativum (Davies, 1984) and Capsicum (Daskalov, 1984). The probable cause of this lack of maternalisation is discussed later.

\section{MUTATION/DAMAGE OR} "CHROMOSOME REPAIR"?

Werner et al. (1984) used the same strain of $N$. rustica $(2 n=48)$ as female parent as that used by Jinks et al. (1981) and Caligari et al. (1981), and sublethally irradiated pollen from $N$. paniculata $(2 n=24)$ and another strain of $N$. rustica, and made a comparative cytological and morphological study of the M1 and F1 hybrids. In the interspecific cross, where there were few defined marker genes available for study, these authors state that the M1 plants whilst showing more variation, were in general similar in phenotype to the normal, roughly intermediate, F1 hybrids, and "no maternal trends were apparent". Yet, in the one defined character for which the two species are clearly distinguishable and for which numerical data were given, the dominant green flower and plant colour of $N$. paniculata, the $\mathrm{F} 1$ hybrids all showed the dominant character of the pollen parent, but 11 of the $56 \mathrm{M} 1$ hybrids (over 20 per cent) lacked the dominant character, i.e., showed the maternalisation effect. In interspecific hybrids involving relatively distant species having few known gene markers and different chromosome numbers, and where the hybrids (triploids) might also show abnormal phenotypes owing to mitotic chromosomal instability, it may be difficult to visualise maternalisation effects caused by single gene, or small segmental, differences. Nevertheless, considering observations on a single definitive character for which precise numerical data are available, it may be concluded that the phenomenon of maternalisation does occur in this combination.

Werner et al. similarly give a blanket description of M1 phenotypes resulting from intraspecific crosses in $N$. rustica. They state that "although many of these plants differ morphologically from the unirradiated hybrid they are not more maternal in appearance, though some individual characters may be". To the present author the elegant, detailed observations of Jinks et al. and Caligari et al. on the same materials, which led them to demonstrate maternalisation effects in the progeny, are too overwhelming and convincing (Mather, 1981; Davies, 1981) to be capable of dismissal in such a manner.

None of the cytological (Snape et al., 1983; Werner et al., 1984; Werner and Cornish, 1984) or the morphological observations made by various authors are contrary to what might be expected on the basis of the theory of chromosome repair through somatic recombination and gene conversion (Pandey, 1983a). Werner et al. (1984) observed that the triploid karyotypes of many of the interspecific progeny showed that "after $20 \mathrm{~K}$ rads of $\gamma$-radiation the chromosomes of some pollen grains of $N$. paniculata remain essentially intact and unfragmented". It seems extremely unlikely that at such high doses the whole chromosome complement of a pollen grain could remain substantially undamaged. Rather, it is more likely that some, rare, pollen grains are damaged to a lesser extent than most, and the damage is generally of such a character that it could be largely repaired through somatic recombination and gene 
conversion during early embryogeny. Such repaired, "maternalised", paternal chromosomes in M1 plants arising from fertilisation by lesserdamaged pollen grains may appear essentially normal. In intraspecific combinations, these M1 plants may not only show maternalisation effects but may also be relatively fertile, as observed by various authors.

Werner et al. have sugested that radiationinduced mutation/damage could be transmitted from the $M 1$ to the $M 2$ generation, and since this would generally lead to a loss of function in the paternal genome it would result in lack of vigour and fertility in the $\mathbf{M} 2$, explaining previously observed results. The recent results of Caligari et al. (1984) on barley are most decisive on this matter. Their detailed observations on four continuously varying characters clearly show that there is no such lack of vigour or fertility in the M2 generation. As expected on the basis of earlier observations concerning untransferability to the next generation, of radiation-induced deletions in the pollen, the data are unequivocal in demonstrating that the "damaged" segment of the paternal genome is in fact absent in the M2 generation, and that the phenomenon of maternalisation is a real one, producing the excess of natural, maternal phenotypic variation. Indeed, in a later study, Werner and Cornish (1984) observed that the intensity of selection against the aberrations was insufficient to explain the magnitude of the maternal trend in the M2. The data thus strongly support the theory that truly maternalised "repaired" paternal chromosomes, rather than radiation"damaged" paternal chromosomes per se, lie behind the observed phenomenon.

It must be noted that the above authors (Werner et al., 1984; Werner and Cornish, 1984; Caligari et al., 1984), using sublethal irradiation, were all apparently unaware of the present author's explanation of "maternalisation" based on chromosome repair theory involving somatic recombination and gene conversion (Pandey, 1983a), and mistakenly continued to apply to their work the present author's earlier explanation given for "selective transformation" obtained with the use of lethal irradiation. The present author never suggested that explanations for the results of lower sublethal and high lethal dose applications were the same. The two phenomena were always considered to be distinct.

\section{"CHROMOSOME REPAIR"- MITOTIC AND MEIOTIC?}

If M1 maternalisation results from "repair" of damaged paternal chromosomes with the aid of normal maternal chromosomes, it is possible that meiotic as well as mitotic recombination may play a part in this repair. A recent study by Gerats $e t$ al. (1984) in Petunia hybrida has suggested that to a very limited extent this indeed is probably the case. Using sublethally irradiated pollen $(10 \mathrm{Kr})$ from paternal parents bearing three dominant markers and triple homozygous recessives as maternal parents, these authors showed that for one gene there was a recovery of about 3.3 per cent recessives in the $M 1$, which could all be ascribed to chromatid breaks producing terminal deletions. Virtually no mutations were found for the other two genes (among 891 M1 plants studied there was a single mutation affecting one gene). Karyotype analysis and genetic data concerning the gene that yielded a significant number of mutants showed that at least 75 per cent of these mutants contained a detectable deletion on the short arm of the chromosome VI bearing this gene. The deletions ranged from "non-detectable" (that is a non-transmissable mutant, showing no visible deletion) to the complete short arm. Deletionbearing chromosomes, as expected from previous studies mentioned above, were not transmitted to the next generation, neither through the male nor through the female. However it was shown that transmission of dominant markers located on the long arm of chromosome VI was possible at a "low to very low" rate, presumably after completion of the deletion-bearing chromosome by crossing-over at meiosis. An earlier study in tomato, similarly revealed maternalisations of $1 \cdot 1$ per cent and $1 \cdot 2$ per cent respectively for two genes studied which could entirely be ascribed to chromatid breakinduced terminal deletions (Rick and Khush, 1961). These two studies suggest that maternalisation of up to 3.3 per cent for certain genes in the M1 can be obtained through the use of irradiated pollen which can be accounted for by terminal deletion; and that gametic selection at M1 meiosis, eliminating damaged paternal chromosomes or genetic segments, can to a very small extent contribute to maternalisation in the $\mathbf{M} 2$, as also proposed by Zamir (1983).

The above study, however, does not explain the very high degree of single gene maternalisations (10-over 60 per cent) in the M1 generation found in a number of species studied, as summarised in table 1. While both kinds of breaks, chromatid and subchromatid, involving single breaks, may contribute to maternalisation in the M1 (fig. 1) the contribution of chromatid breaks is considered very minor, and gene specific, subchromatic lesions being up to 10 or more times more effective. More importantly, in contrast to 
Table 1. Three classes of plants according to the degree of maternalisation observed following use of sublethally irradiated pollen

\begin{tabular}{|c|c|c|c|c|}
\hline Species & $\begin{array}{l}\text { Number of } \\
\text { genes studied }\end{array}$ & Single & aternal & M1 \% \\
\hline \multicolumn{5}{|l|}{ Class 1} \\
\hline Wheat (T. aestivum) & 2 & $35 \cdot 9$ & \multirow{5}{*}{$10 \cdot 3$} & $33 \cdot 5$ \\
\hline Barley (H. vulgare) & 2 & $67 \cdot 2$ & & $30 \cdot 7$ \\
\hline Maize ( $Z$. mays) & 3 & $12 \cdot 5$ & & $7 \cdot 4$ \\
\hline Indian mustard (B. juncea) & 2 & $50 \cdot 0$ & & $47 \cdot 6$ \\
\hline Nicotiana rustica & - & $38 \cdot 0 \|$ & & \\
\hline $\begin{array}{l}\text { Nicotiana rustica } \$ \\
\times N . \text { paniculata } \delta\end{array}$ & 1 & $19 \cdot 6$ & & \\
\hline \multicolumn{5}{|l|}{ Class 2} \\
\hline Pea $(P$. sativum $)$ & 5 & \multicolumn{3}{|c|}{ All 0} \\
\hline Capsicum & 4 & \multicolumn{3}{|c|}{ All $0^{*}$} \\
\hline $\begin{array}{l}\text { Lycopersicon esculentum } 9 \\
\times \text { Solanum pennellii } \delta\end{array}$ & 7 & \multicolumn{3}{|c|}{ All $0 \dagger$} \\
\hline \multicolumn{5}{|l|}{ Class 3} \\
\hline Tomato (L. esculentum) & 2 & $1 \cdot 2$ & & $1 \cdot 1$ \\
\hline Petunia hybrida & 3 & $3 \cdot 3$ & 0 & $0 \ddagger$ \\
\hline
\end{tabular}

* Virtually nil (for three genes all 0 , one gene-1 in 105 plants).

$\dagger$ Virtually nil (six genes-all 0 , one gene-1 in 112 plants).

$\ddagger$ Virtually nil (two genes both 0 , one gene-1 in 891 plants).

I In tomato, intraspecific crosses gave a very low maternalisation based on terminal deletions but interspecific crosses, when tomato was used as female, gave virtually no maternalisation (Class 2).

$\|$ Per cent of M1 plants showing maternal characters.

the chromatid-break deletions which are usually not transmissable to the next sexual generation (Gerats et al., 1984), the maternalisation caused by subchromatid lesions may be totally transmissible to the M2 generation in the normal manner, thus accounting for very high maternalisation in the M2 as well, for example in $N$. rustica. The role of intercalary deletions which require two appropriate breaks simultaneously is probably not significant in this maternalisation, as evidenced by the studies in tomato (Rick and Khush, 1961) and $P$. hybrida (Gerats et al., 1984). The comparative effect on maternalisation of particulate ionising radiations (electrons, protons, neutrons and alpha particles), which favour chromatid breaks as against presently used electromagnetic radiations (X-rays and gamma rays) which favour subchromatid breaks (Upton, 1982), is not known.

Since there is normal fertilisation and there is no individual gene or chromatin segment transfer, as in "transformation", the resulting maternalisation phenomenon, involving alteration in the expected pattern of maternal and paternal genes and affecting both quantitative and qualitative characters, may be called "accentuated genetic transfer", distinguishing it from the transformation based "gene transfer".

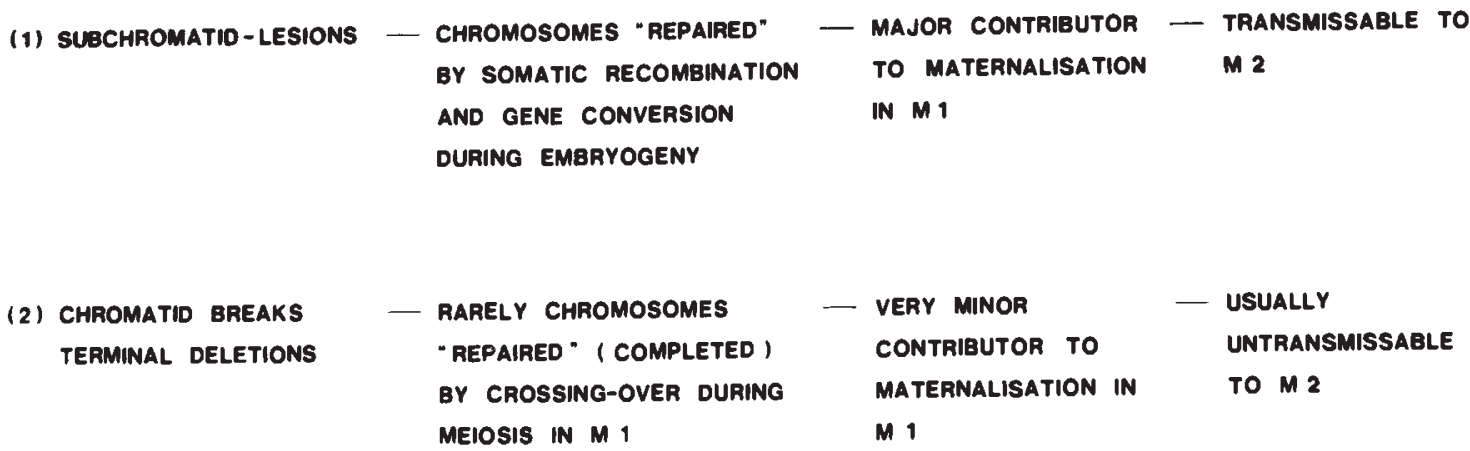

Figure 1 Maternalisation in relation to the two kinds of chromosome breaks. 
THREE CLASSES OF PLANTS

The 11 species in which sublethally irradiated pollen has been used so far can be grouped into three classes (table 1): Class 1, in which the irradiated pollen produces a high maternalisation effect as described above. To this class belong $N$. rustica, $N$. paniculata, $Z$. mays, $H$. vulgare, $T$. aestivum and $B$. juncea. Class 2 , in which the M1 progeny are not variable in the defined characteristics and are very similar to the normal F1 progeny, and there is no maternalisation or dosage effect. To this class belong $P$. sativum, $S$. pennellii and Capsicum. Class 3 , in which the M1 progeny are variable but to a much smaller degree than is found in Class 1 . To this class belong $L$. esculentum and $P$. hybrida.

What may be the cause of this distinction between the three classes of species? Since damage to DNA through sublethal irradiation of mature pollen does not appear to have any signifiant adverse effect on pollen germination or pollen tube growth, the elimination of deficiencies and gross chromosomal changes may occur chiefly through defective fertilisation, zygotic or embryo abortion, or through mitotic elimination of damaged chromosomes or chromosome parts in embry. ogeny. This may lead generally, as regards marker genes, to phenotypically similar, relatively uniform, M1 plants. Such a "clearing mechanism" would indeed explain the similarity of M1 and F1 hybrids in the class 2 plants. In this case, presumably, neither the chromatid nor subchromatid breaks are recovered in the M1 progeny (fig. 2).
Rick and Kush (1969) and Gerats et al. (1984) have suggested that chromatid breaks effecting deletions involving arms that contain genes concerned with the gametogenesis and fertilisation processes would not be recovered in the M2, but such deletions have no effect on the M1 generation itself, presumably because, as discussed elsewhere, (Pandey, 1980c, 1983b), the products of genes controlling gametogenesis, pollen tube growth and fertilisation are already laid down in the cytoplasm in the meiocytes or earlier diploid phase, before irradiation. Possibly two of the three genes studied in $P$. hybrida (Gerats et al., 1984) involved regions in the genome essential for the sporophytic generation including seed development, thus accounting for the lack of recovery of chromatid break deletions in the M1.

Why, then, is there so much variation and maternalisation of the M1 progeny in the class 1 species? In these cases there does not appear to be severe elimination of the radiation-induced genetic deficiencies or lesions, as expressed in the M1 phenotypes. A considerable amount of genetic deficiency appears to be tolerated and expressed. The M1 progeny, by and large, behaves as if it is homozygous for the maternal recessive allele. The deficiencies are not only able to be "harvested" by the breeder but in some way the residual damage is being removed so that it does not, in general, lead to lethality and gross abnormality. The inescapable conclusion, embodied in the theory of chromosome repair through somatic recombination and gene conversion (Pandey, 1983a, 1984),

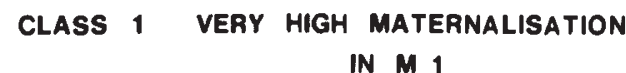

IN M 1

\section{SUBCHROMATID BREAK DEFICIENCY ALONE,}

OR

\section{BOTH DEFICIENCIES, INCLUDING \\ CHROMATID BREAK, RECOVERED}

\section{NEITHER DEFICIENCY \\ RECOVERED}

\begin{abstract}
CLASS 2
NO MATERNALISATION

IN M 1

CLASS 3 VERY LOW MATERNALISATION IN $M 1$
\end{abstract}

ONLY ONE
- CHROMATID BREAK - TERMINAL DEFICIENCY RECOVERED

TRANSMISSABLE

TO $M 2$ 
is that the radiation-induced subchromatid lesions in the paternal chromosomes are being repaired, with homologous maternal chromosomes being used as templates.

In the class 3 species $L$. esculentum and $P$. hybrida, the genes concerned with chromatid break-induced deletions are presumably not in the arms containing genes essential for sporophytic development. Such deletions are therefore recovered in the M1 (fig. 2). There is, however, no recovery of losses due to subchromatid breaks.

\section{HYPOTHESIS}

But why do class 1 species, at least the strains used in the said studies, carry this facility for subchromatid break chromosome repair whereas those in the classes 2 and 3 apparently do not? There are various systems of DNA repair, each requiring its own specific array of enzymes to mediate different steps (Boyd and Setlow, 1976). Ineffective "polymorphism" (used in a wider sense, including functional polymorphism involving a set of genes as well as single gene polymorphism) or deficiency, in any one of the genetic systems responsible for the enzymes in the pathway may stop or seriously hamper the processes of repair. Although DNA repair systems have been found in prokaryotes and have also been shown to occur in certain animal and plant cells, it is evident from the review of literature (Wolff and Cleaver, 1973; Yamaguchi et al., 1975; Kihlman, 1977; Tano and Yamaguchi, 1977; Soyfer, 1979; Jackson and Linskens, 1980; Johnson et al., 1984) that the belief, by some authors, of their relatively uniform, universal occurrence, with regard to tissues as well as species, in plants may not be justified. The notion that DNA repair as a process is common to all life, and evolved very early, is generally accepted. What is proposed here is that variability may occur in specific type and extent of DNA repair associated with the species, the phase of development and tissue concerned, and the source and type of DNA damage. While certain systems of repair, e.g., those involved with fidelity of replication and possibly meiotic recombination, may be universal, the same may not be true for other systems. The existence of frequent contradictory evidence seems to suggest that certain plant species or strains may either lack or have varyingly inefficient "excision repair" mechanisms in certain tissues (Pandey, 1984). Plants may not only differ in the systems and quality and extent of repair, but also in the conditions under which an existing system may express itself (Soyfer, 1983).
Plants might differ from animals regarding this facility because of the totipotency of their cells, alternation of generations, multiple forms of reproduction, and "open" growth system-some of this evolutionarily related to their predominantly fixed physical existence-which allow them resiliency in regeneration and survival that is not possible in animals. In the latter, having an integrated body physiology, "closed" growth system and a cellular circulatory mechanism, an irregularity arising in a single cell may eventually cause disease or even death, affecting the whole individual. The scope of DNA repair enzyme variation and "polymorphism" in animals must, therefore, of necessity, be restricted. In plants, with their compensatory, rejuvenating growth mechanisms such single cell disorders, ordinarily, would have little effect on the individual as a whole. Plants, therefore, can afford to be relatively more lax in their DNA repair facilities as compared to animals.

It is therefore suggested that DNA repair, particularly "excision repair", is a significant factor in chromosome repair through somatic recombination and gene conversion, where, clearly, excision of the damaged strand and unscheduled replication of the homologous, normal, maternal segment would be an integral part of the repair system. The class 1 species, or strains used, may not possess in the pollen the necessary repair enzymes for this type of repair whereas the classes 2 and 3 species may possess them (table 1 and fig. 2). The pollen might thus vary between species and strains regarding the DNA repair facility, so that, for example, in peas, tomato and Petunia, where all DNA damage might be repaired soon after irradiation of pollen, there is no opportunity for somatic recombination and gene conversion after fertilisation, and there is no maternalisation, whereas in class 1 species where DNA repair does not occur in the pollen, or occurs to a limited extent, there is opportunity for recombination and gene conversion after fertilisation, and there is maternalisation. Variation in maternalisation in the different materials may thus reflect variation in the DNA repair facility specifically in the pollen, and not in the overall facility in the somatic tissue.

\section{Pollen cytology and "accentuated genetic transfer"}

The present theory is also perfectly in accord with observations on pollen cytology (Brewbaker, 1959; Pandey, 1960, 1970). The suggestion that the nutritionally restricted male gametophyte (pollen), where at least one nuclear division occurs without 
cell division, might be deficient in the facility for DNA repair, as compared to the sporophyte, is supported by the results reviewed here; for it would mean that the trinucleate pollen, which has to undergo two nuclear divisions in the same protoplasm, would be even more deficient than the binucleate pollen. Thus the binucleate species, having comparatively less deficient pollen, may or may not be able to repair all its radiation-induced DNA damage in the pollen but the trinucleate species, having far poorer pollen, would almost certainly fail to do so. The fact that all four trinucleate species studied so far-wheat, barley, maize and Brassica-show maternalisation while only two ( $N$. rustica and $N$. paniculata) out of seven binucleate species-pea, Capsicum, tomato, S. pennellii Petunia, N. rustica and $N$. paniculata-does, substantiates this proposal. In $N$. rustica and $N$. paniculata, at least a significant proportion of DNA damage is believed to remain unrepaired, allowing the opportunity for this damage to be repaired after fertilisation during embryogeny and thus giving maternalisation (table 1). It is interesting to note that one species, Petunia hybrida, which has binucleate pollen and which has been studied for DNA repair enzymes in the pollen, shows the presence of such enzymes (Jackson and Linskens, 1978, 1979), as expected. Comparative studies of DNA repair enzymes in the pollen in a few binucleate and trinucleate pollen species should be decisive. The theory suggests that trinucleate species including some of the most economically important families of plants, e.g., Gramineae (cereals and grasses), Cruciferae (vegetables, oil and fodder crops) and Compositae (vegetables, oils and ornamentals) would almost all show accentuated genetic transfer, while only a few binucleate species would do so.

\section{Pollen grains and the lethal dose of radiation}

The present proposition also explains another intriguing phenomenon in plants-very large differences in species sensitivity of pollen grains to ionising radiation, as assessed from viable seeds produced after the use of irradiated pollen. For example, the lethal does for Pisum sativum, Hordeum vulgare, Triticum aestivum and Capsicum is between 3-5 Kr whereas for Nicotiana rustica, $N$. paniculata, N. langsdorffi, $N$. alata, N. glutinosa, Lycopersicon esculentum and Solanum pennellii it may be as much as 10 times higher, between $20-$ $30 \mathrm{Kr}$ (Virk et al., 1977; Pandey and Phung, 1982; Snape et al., 1983; Powell et al., 1983; Zamir, 1983; Davies, 1984; Daskalov, 1984; Werner et al., 1984). It is interesting to note that in the same family
Solanaceae, Capsicum belongs to the highly sensitive group while $S$. pennellii, $L$. esculentum and all 5 species of Nicotiana examined belong to the more resistant group. In an organism endowed with the natural, comprehensive array of DNA repair enzymes most of the DNA breaks are rejoined speedily, about half within a few minutes after irradiation and most finishing within two hours (Kemp et al., 1984). The ability for speedy repair of damaged DNA strands may be a critical factor in determining the viability of the male gametes after irradiation of the pollen. Different sets of enzymes are needed to complete repairs of specific types of damage (Witkin, 1975). Plants may be particularly variable in this respect. Following irradiation of pollen, plant species or strains may therefore vary strikingly in the two phenomena, degree of male gamete viability and accentuated geneiic transfer, for the same reasonvariation and "polymorphism" of specific chromosome and DNA repair enzymes. In the Solanaceae, $N$. rustica and $N$. paniculata show accentuated genetic transfer whereas Capsicum, Lycopersicon esculentum, S. pennellii and Petunia hybrida do not. The two phenomena are at least partly independent, as is seen from the lack of relationships in the materials studied. Of four species which have a very low pollen gamete viability after irradiation, $H$. vulgare and $T$. aestivim show accentuated genetic transfer while Pisum sativum and Capsicum do not.

\section{CONCLUSIONS}

Heritable mutation/damage, mainly deletion, is unlikely to be the principal basis for accentuated genetic transfer in the M1 and M2 because: (a) The frequency of single gene deletions (10-60 per cent or more) required to explain observed maternalisations is too high for viable, fertile progeny to occur; (b) both quantitative and qualitative characters are affected; (c) the observed deletions, in tomato and Petunia, are too gene specific and too infrequent (1-3.3 per cent) to account for the very high and varied maternalisations obtained in a number of species; and, very significantly, (d) the deletion-bearing chromosomes are usually not transmissable to the next sexual generation (M2). The concept that the radiation-damaged segment of the paternal genome (deletions, mutations and chromosome rearrangements) which would survive and be expressed in the M1 but would normally be eliminated at the M1 meiosis and thus might account for high maternalisation of $\mathrm{M} 2$, as compared to unirradiated F2, (Zamir, 1983; Snape 
et al., 1983; Werner, et al., 1984) also appears to be untenable for, in general, most observations have shown that the extent of variation in the M1 and M2 is in fact related. Significantly, it does not account for the maternalisation of M1 plants themselves. Furthermore, it does not explain the large variability between the species studied. If it is a result of such a normal cytological phenomenon, the huge variability between species is inexplicable. The theory of chromosome repair through somatic recombination and gene conversion with the attendent requirement of specific chromosome and DNA repair enzymes, for which plants are believed to be highly variant in the pollen, on the other hand, can account for all the recorded observations.

If the present interpretation is correct, the class 1 species, maize, barley, wheat, Nicotiana rustica, $N$. paniculata and Brassica juncea (trinucleate pollen species in general) may be suitable materials for breeding, particularly for interspecific gene transfer, by the sublethal pollen-irradiation technology, and the class 2 and 3 species, tomato, $P$. hybrida, pea, S. pennellii and Capsicum (binucleate pollen species in general), may not. The work in maize (Pandey, 1983a) suggests that there may be variation between different strains of the same species in the extent of positive response of this facility. So, at present, with the paucity of information, only a preliminary trial experiment can determine the potential of a particular combination. Happily, the state of the M1 variation appears to be a clear guide in distinguishing the phenomenon.

Acknowledgements I thank Drs Margot Forde and Clive Ronson for reading the manuscript and making helpful suggestions. The author is especially grateful to Professor H. J. Evans (Clinical and Population Cytogenetics Unit, Western General Hospital, Edinburgh, U.K.), for his kind permission to cite one of his key diagrams-on the relationship between the types of aberrations induced by ionising radiations, DNA synthesis and stage in development of mitotic cycle-in an earlier paper by the author (MGG 191: 358-365, 1983), and whose inspiring research and scholarship on the subject greatly helped in the formulation of the present "DNA repair theory".

Dedication This paper is dedicated to my wife Kanti Pandey in appreciation of her continuing valuable support during these exciting investigations.

\section{REFERENCES}

BANGA, S. S., BANGA, S. K. AND LABANA, K. S. 1984. Gametic gene transfer in Indian mustard (Brassica juncea (L.) Coss.). Heredity, 53, 293-297.

BOYD, J. B. AND SETLOW, R. B. 1976. Characterization of postreplication repair in mutagen-sensitive strains of Drosophila melanogaster. Genetics, 84, 507-526.
BREWBAKER, J. L. 1959. Biology of the angiosperm pollen grains. Indian J. Genet. \& Pl. Breed., 19, 121-133.

BREWBAKER, J. L. AND EMERY, G. C. 1962. Pollen radiobotany. Radiat. Bot., 1, 101-154.

CALIGARI, P. D. S., INGRAM, N. R. AND JINKS, J. L. 1981. Gene transfer in Nicotiana rustica by means of irradiated pollen. I. Unselected progenies. Heredity, 47, 17-26.

CAligari, P. D. S., POWELl, W. AND HAYTER, A. M. 1984. Quantitatively varying characters in the second generation from an irradiated pollen cross in barley. Heredity, 52, 347-353.

D'AMAто, F. 1977. Nuclear Cytology in Relation to Development. Cambridge Series 6, Cambridge Univ. Press.

DASKAlOV, S. 1984. Pollen irradiation and gene transfer in Capsicum. Theor. Appl. Genet., 68, 135-138.

DAVIES, D. R. 1981. Gene transfer in plants. Nature, 291, 531532.

DAVIES, D. R. 1984. Pollen irradiation and the transfer of maternal genes in Pisum sativum. Theor. Appl. Genet., 67, 245-248.

DRESSLER, D. AND POTTER, H. 1982. Molecular mechanisms in genetic recombination. Annu. Rev. Biochem., 51, 727 761.

ESPOSITO, M. S. AND WAGSTAFF, J. E. 1981. Mechanisms of mitotic recombination. Strathern, J., Jones, E., and Broach, J. (eds.). In The Molecular Biology of the Yeast, Saccharomyces, Cold Spring Harbor, New York.

EVANS, H. J. 1962. Chromosome aberrations induced by ionising radiation. Int. Rev. Cytol., 13, 221-308.

FOGEL, S., MORTIMER, R. K. AND LUSNAK, K. 1983. Meiotic gene conversion in yeast: Molecular and experimental perspectives. Spencer, J. F. T., Spencer, D. M. and Smith, A. R. W. (eds.). In Yeast Genetics, Springer-Verlag, New York, pp. 65-107.

GERATS, G. M., VLAMING, P. DE AND MAIZONNIER, D. 1984. Recombination behaviour and gene transfer in Petunia hybrida after pollen irradiation. Mol. Gen. Genet., 198, $57-61$.

JACKSON, J. F. AND LINSKENS, H. F. 1980. DNA repair in pollen: Range of mutagens inducing repair, effect of replication inhibitors and changes in thymidine nucleotide metabolism during repair. Mol. Gen. Genet., 180, 517-522.

JINKS, J. L., CALIGARI, P. D. S. AND INGRRAM, N. R. 1981. Gene transfer in Nicotiana rustica using irradiated pollen. Nature, 291, 586-588.

JOHNSON, R. T., COLLINS, A. R. S., ELLIOT, G. C. AND SQUIRES, S. 1984. Comparative studies of repair using inhibitors. Collins, A., Downes, C. S. and Johnson, R. T. (eds.) In DNA Repair and its Inhibition, IRL Press, Oxford, pp. 255-277.

KIHLMAN, B. A. 1977. Caffeine and Chromosomes. North Elsevier Publ. Co., Amsterdam.

KEMP, L. M., SEDGWICK, S. G. AND JEGGO, P. A. 1984. X-ray sensitive mutants of Chinese hamster ovary cells defective in double-strand break rejoining. Mutat. Res., 20, 71-76.

LEIGH, B. 1976. Ring chromosomes and radiation induced chromosome loss. Ashburner, M. and Novitski, E. (eds.), In The Genetics and Biology of Drosophila, Vol. 1b, Acadamic Press, London, pp. 505-528.

MATHeR, K. 1981. Perspective and prospect. Phil. Trans. $R$. Soc. Lond. B., 292, 601-609.

MITTLER, S. 1982. Effect of hyperthermia on radiation-induced chromosome loss in female Drosophila melanogaster. J. Hered., 73, 451-456.

ORTON, T. J. AND STEIDL, R. P. 1980. Cytogenetic analysis of plants regenerated from colchicine-treated callus cultures of an interspecific Hordeum hybrid. Theor. Appl. Genet., $57,89-95$ 
PANDEY, K. K. 1960. Evolution of gametophytic and sporophytic systems of self-incompatibility in angiosperms. Evolution, 14, 98-115.

PANDEY, K. K. 1970. Time and site of the $S$-gene action, breeding systems and relationships in incompatibility. Euphytica, 19, 364-372.

PANDEY, K. K. 1975. Sexual transfer of specific genes without gametic fusion. Nature, 256, 310-313.

PANDEY, K. K. 1978. Gametic gene transfer in Nicotiana by means of irradiated pollen. Genetica, 49, 53-69.

PANDEY, K. K. 1980a. Further evidence for egg transformation in Nicotiana. Heredity, 45, 15-29.

PANDEY, K. K. 1980b. Parthenogenetic diploidy and egg transformation induced by irradiated pollen in Nicotiana. $N Z$. J. Bot., 18, 203-207.

PANDEY, K. K. $1980 c$. Resistance of male gametic function to ionising radiation: Implication in evolution and in induced transformation in higher organisms. NZ. J. Sci, 23, 361364.

PANDEY, K. K. 1981. Egg transformation and parthenogenetic diploidy induced through the aid of ionising radiation: Theory and practice. In Induced mutations as a tool for crop plant improvement, IAEA-SM-251/39, Vienna, pp. 49-65.

PANDEY, K. K. 1983a. Evidence for gene transfer by the use of sublethally irradiated pollen in Zea mays and theory of occurrence by chromosome repair through somatic recombination and gene conversion. Mol. Gen. Genet., 191, 358-365.

PANDEY, K. K. 1983b. Cytogenetical bases of self-incompatibility: Evolutionary considerations. Swaminathan, M. S., Gupta, P. K. and Sinha, U. (eds.). In Cytogenetics of crop plants, Macmillan India Ltd, Delhi, pp. 117-156.

PANDEY, K. K. 1984. Intra- and interspecific gene transfer through the use of irradiated pollen-sublethal irradiation. In Proceedings International Symposium on Genetic Manipulation in Crops, October 22-26, 1984, Beijing, China (in press).

PANDEY, K. K. AND PATCHELL, M. R. 1982. Genetic transformation in chicken by the use of irradiated male gametes. Mol. Gen. Genet., 186, 305-308.

PANDEY, K. K. AND PHUNG, M. 1982. 'Hertwig Effect' in plants: Induced parthenogenesis through the use of irradiated pollen. Theor. Appl. Genet., 62, 295-300.

POWELL, W., CALIGARI, P. D. S. AND HAYTOR, A. M. 1983. The use of pollen irradiation in barley breeding. Theor. Appl. Genet., 65, 73-76.
RICK, C. M. AND KHUSH, G. S. 1961. X-ray induced deficiencies of chromosome 11 in the tomato. Genetics, 46, 1389-1393.

RICK, C. M. AND KHUSH, G. S. 1969. Cytogenetic explorations in the tomato genome. Bogarat, R. (ed.), In Genetic Lectures Vol. 1, Oregon Univ. Press, Eugene, pp. 45-69.

SNAPE, J. W., PARKER, B. B., SIMPSON, E., AINSWORTH, C. C., PAYNE, P. I. AND LAW, C. N. 1983. The use of irradiated pollen for differential gene transfer in wheat (Triticum aestivum). Theor. Appl. Genet., 65, 103-111.

SOYFER, V. N. 1979. DNA damage and repair in higher plants. Lett, J. and Adler, H. (eds.). In Advances in Radiation Research, Academic Press, New York, pp. 219-272.

SOYFER, V. N. 1983. Influence of physiological conditions on DNA repair and mutagenesis in higher plants. Physiol. Plant., 58, 373-380.

TANO, S. AND YAMAGUCHI, H. 1977. Repair of radiationinduced single-strand breaks in DNA of barley embryo. Mutat. Res. 42, 71-78.

UPTON, A. C. 1982. The biological effects of low-level ionising radiation. Sci. Amer., 246, 29-37.

VASSILEVA-DRYANOVSKA, O. A. 1966. Development of embryo and endosperm produced after irradiation of pollen in Tradescantia. Hereditas, 55, 129-148.

VIRK, D. S., DHAHI, S. J. AND BRUMPTON, R. J. 1977. Matromorphy in Nicotiana rustica. Heredity, 39, 287-295.

WERNER, C. P. AND CORNISH, M. A. 1984. Gene transfer in Nicotiana rustica by means of irradiated pollen. III. Cytogenetic consequences in the second generation. Heredity, 53, 545-551.

WERNER, C. P., DUNKIN, I. M., CORNISH, M. A. AND JONES, G. H. 1984. Gene transfer in Nicotiana rustican by means of irradiated pollen. II. Cytogenetical consequences. Heredity, 52, 113-119.

WITKIN, E. M. 1975. Relationship among repair, mutagenesis and survival: Overview. Hanawalt, P. C. and Setlow, R. B. (eds.). In Molecular Mechanisms for Repair of DNA, Plenum Press, New York, pp. 347-358.

WOLFF, S. AND CLEAVER, J. E. 1973. Absence of DNA repair replication after chemical mutagen damage in Vicia faba. Mutat. Res., 20, 71-76.

YAMAGUCHI, H., TATARA, A. AND NAITO, T. 1975. Unscheduled DNA synthesis induced in barley seeds by gamma rays and 4-nitroquinoline 1-oxide. Japan J. Genet., 50, 307-318.

ZAMIR, D. 1983. Pollen irradiation in tomato: minor effects of enzymic gene transfer. Theor. Appl. Genet., 66, 147-151. 